\title{
Gastro-oesophageal reflux prevalence and relationship with bronchial reactivity in asthma
}

\author{
D. Vincent*, A.M. Cohen-Jonathan*, J. Leport+, M. Merrouche+, A. Geronimi*, \\ A. Pradalier*, J.C. Soulé ${ }^{+}$
}

Gastro-oesophageal reflux prevalence and relationship with bronchial reactivity in asthma. D. Vincent, A.M. Cohen-Jonathan, J. Leport, M. Merrouche, A. Geronimi, A. Pradalier, J.C. Soulé. @ ERS Journals Ltd 1997.

ABSTRACT: The relationship between asthma and gastro-oesophageal reflux (GER) is controversial. In an allergy department, GER prevalence was evaluated in asthmatics, with a view to judging the potential influence of GER on asthma.

One hundred and five asthmatics were recruited and co-investigated for GER and lung function. Descriptive analysis was performed, patients with (GER+) and without (GER-) GER were then compared, and finally, stepwise regression analysis was used. GER prevalence was $32 \%$.

Lung parameters did not differ between GER+ and GER- patients. When restricting analysis to GER+ patients, bronchial reactivity was closely correlated to the number of reflux episodes (NRE) $(r=0.983 ; p=0.001)$. When comparing patients with more than 15 reflux episodes ${ }^{-1 a y}{ }^{-1}(n=50)$, with those having less $(n=43)$, no differences were found in lung function and GER parameters. However, there was a positive correlation between the provocative dose of methacholine causing forced expiration volume to fall $20 \%$ from the baseline and NRE in patients with NRE $>15(r=0.561 ; p=0.05)$.

In conclusion, gastro-oesophageal reflux was observed in a third of the asthma patients studied. These data do not support a firm aetiological relationship between gastro-oesophageal reflux and asthma, but do suggest an association between the number of reflux episodes and bronchial hyperresponsiveness.

Eur Respir J 1997; 10: 2255-2259.
* Service de Médecine Interne et Centre d'Allergie, and +Service de Gastroentérologie, Hôpital Louis Mourier, 178 rue des Renouillers, 92700 Colombes, France.

Correspondence: D. Vincent

Hôpital Louis Mourier

178 rue des Renouillers 92700 Colombes

France

Keywords: Asthma bronchial hyperresponsiveness gastro-oesophageal reflux prospective study

Received: January 21997 Accepted after revision June 301997
Asthma is a bronchial disease characterized by an inflammatory process [1]. Gastro-oesophageal reflux (GER) has been suspected as a causal factor, but the relationship between GER and asthma remains controversial.

The physiopathological mechanisms involved in this potential relationship are still hypothetical [2-4], although two main mechanisms are usually accepted, reflex [5-7] or acid inhalation [8-10]. A possible relationship between the severity of GER and that of asthma has not been investigated previously.

GER prevalence is not precisely known in asthmatics; it has been estimated at levels of 20 to even $80 \%$ [11]. Finally, it is not known which groups of asthma patients in particular should be investigated for GER.

This controversy induced us to conduct a prospective assessment of GER prevalence in a population of 105 consecutively admitted asthmatic out-patients and to search for a relationship between the development of asthma and that of GER.

\section{Materials and methods}

\section{Patients}

One hundred and five consecutively admitted asthmatic out-patients were investigated. Asthma was diag- nosed according to international consensus guidelines [12]. Besides clinical data, airway obstruction was measured and its reversibility was defined as a $20 \%$ improvement in forced expiratory volume in one second (FEV1) after bronchodilator administration, or a $20 \%$ decrease in FEV1 after methacholine bronchoprovocation. FEV1 was measured with a pocket-sized spirometer (Spirobank®; Isotec, Saint-Quentin, France). Results were expressed in real values and as the percentage of standard values for age, gender and height [13]. Bronchoprovocation tests were performed in accordance with the American Thoracic Society guidelines [14]. Methacholine was provided by Allerbio (Varennes en Argonne, France) and administered with a breath-activated nebulizer (Pulmo-neb FDC 88; MSR, Rungis, France) and increasing doses in the range $0.02-43 \mu \mathrm{M}$. The provocation test was stopped when FEV1 had fallen by $20 \%$ from the postsaline value. FEV1, mean expiratory flow (MEF) at 25,50 , and $75 \%$ of vital capacity and provocative dose of methacholine causing a $20 \%$ fall in FEV1 (PD20) were used for statistical analysis and thereby designated as lung function variables.

Asthma was considered to be nonallergic when clinical history, skin-prick tests and nasal allergic provocation were negative. It was considered as allergic when suggested in clinical history and when skin and/or nasal provocation tests were positive. 
Asthma staging was taken from international consensus guidelines [12]: grade $1, \mathrm{FEV} 1>80 \%$; grade 2 and 3, FEV1 60-80\%; grade 4, FEV $1<60 \%$.

Asthma treatment was quantified when patients underwent lung function evaluation, and expressed as $\mu \mathrm{g} \cdot \mathrm{day}^{-1}$ or $\mathrm{mg}$ day $^{-1}$. $\beta_{2}$-agonists were self-administered; their use was quantitatively assessed as puffs month $^{-1}$, then transformed into $\mu \mathrm{g} \cdot \mathrm{month}^{-1}$, then $\mu \mathrm{g} \cdot \mathrm{day}^{-1}$. Treatment was conducted in agreement with international consensus guidelines [12]. Every patient with grade 2, 3 or 4 severity $(n=31)$ was treated with inhaled corticosteroids (ICS), with a mean daily dosage of $492 \pm 79 \mu \mathrm{g}$. Forty six patients used $\beta_{2}$-agonists when needed, with a mean daily dosage of $300 \pm 54 \mu \mathrm{g}$. Ten were receiving theophylline. Analysis according to asthma severity indicated that grade 1 patients $(n=42)$ were using significantly less ICS than grade 2 and 3 patients $(n=29)(370 \pm 96$ versus $722 \pm 141 \mu \mathrm{g} \cdot \mathrm{day}^{-1}$, respectively, $\left.\mathrm{p}=0.04\right)$. $\beta_{2}$-agonist dosage was higher in grade 2 and 3 than in grade 1 patients $\left(517 \pm 104\right.$ versus $190 \pm 57 \mu \mathrm{g} \cdot$ day $^{-1}$ respectively). Allergy was diagnosed in 60 patients (57\%). As expected, the main allergens were dust mites $(60 \%)$ [15].

GER was evaluated through $24 \mathrm{~h}$ oesophageal $\mathrm{pH}$ monitoring, and defined as a drop in oesophageal $\mathrm{pH}$ below 4 lasting longer than $20 \mathrm{~s}$. The diagnosis of GER was based on an acid exposure time $(\mathrm{pH}<4)$ exceeding $4.2 \%$ of the $24 \mathrm{~h}[16,17]$. The number of reflux episodes (NRE) was also monitored over the same period. Oesophageal manometry measuring mean lower oesophageal sphincter pressure ( $\left.P_{\text {oes, }}, \mathrm{sp}\right)$, and upper digestive endoscopy evaluating oesophageal mucosa, were also performed. Acid exposure time, expressed as a percentage of $24 \mathrm{~h}$ with oesophageal $\mathrm{pH}$ under 4, and NRE were used as GER criteria for statistical analysis. Oesophageal manometry and $\mathrm{pH}$ recording techniques are described in more detail elsewhere [18]. Hiatus hernia was diagnosed when gastric folds extended at least $2 \mathrm{~cm}$ above the diaphragmatic hiatus during quiet respiration. Oesophagitis was staged according to Savary's classification [19].

Statistics were computed with Statview 4.5 (Abacus Concepts Inc, Berkeley, CA, USA), on the whole group, and subsequently in the GER-positive patients only. Analysis was initially descriptive, then correlations were sought between lung spirometry data (FEV1, MEF25\%, MEF50\%, MEF75\%, PD20, and GER) criteria (percentage of $24 \mathrm{~h}$ with $\mathrm{pH}<4$, NRE and Poes,lsp. Adjustment was made for age, clinical symptoms of GER and asthma severity. Stepwise regression analysis was performed, using GER parameters and asthma treatment as predictive variables and lung spirometry values as dependent variables. Statistical significance was admitted when the p-value was less than 0.05 .

This study was approved by a local Ethics Committee and every patient gave oral informed consent.

\section{Results}

\section{Patients' characteristics}

Demographic data. Of the 105 consecutive patients enrolled in the study, five declined to complete it, and six did not tolerate the $24 \mathrm{~h} \mathrm{pH}$ monitoring, leaving 94 asthmatic patients for analysis. There were 41 women and 53 men with a mean age of $39.5 \pm 1.5$ yrs.
Lung function and treatment. Mean FEV1 was $84 \pm 4 \%$ whereas MEF $25 \%$ was $49 \pm 6 \%$, MEF50\% 57 $\pm 6 \%$, MEF75\% $65 \pm 6 \%$ of normal values. Forty eight asthmatics were classified in grade 1, 29 patients in grade 2 and 3, and two in grade 4 . No patients were treated with anti-reflux therapy.

GER. In the total asthmatic population studied, the mean percentage of $24 \mathrm{~h}$ with $\mathrm{pH}<4$ was $5.7 \pm 1.4(0-42 \%)$, the mean NRE was $28 \pm 2$ per day $(0-81)$, the mean $P_{\text {oes, }}$ lsp was $2.0 \pm 0.1(0.7-4.0) \mathrm{kPa}(15.3 \pm 0.62(5-30) \mathrm{mmHg})$.

GER was found in 30 patients, i.e. $32 \%$ of the total population studied. In these patients, the mean percentage of $24 \mathrm{~h}$ with $\mathrm{pH}<4$ was $9.9 \pm 1.7(4.2-42) \%$, the mean NRE for $24 \mathrm{~h}$ was $40 \pm 3(2-81)$, and the mean $P_{\text {oes,lsp }}$ was $2.0 \pm 0.2(0.7-4.0) \mathrm{kPa}(15.1 \pm 1.3(5-30) \mathrm{mmHg})$. Fifteen of these 30 patients $(50 \%)$ had no symptoms suggesting GER. Oesophagitis was present in eight patients, five grade 1 , two grade 2 and one grade 4 .

In GER-negative patients, the mean $\%$ of $24 \mathrm{~h}$ with $\mathrm{pH}<4$ was $1.4 \pm 0.14$, the mean NRE for $24 \mathrm{~h}$ was $20.7 \pm 2.1$; mean $P_{\text {oes, }}$,sp $(2.1 \pm 1.4 \mathrm{kPa}(15.8 \pm 10.7 \mathrm{mmHg}))$ was not different from that in GER-positive patients.

\section{Relationship between GER and lung function in the whole population}

Comparison of asthmatics with and without GER showed no significant difference in spirometry parameters and drug intake (table 1). PD20 was lower in GER-positive than in GER-negative patients, but this difference was not statistically significant $(p=0.23)$. In the whole population studied, there was no correlation between spirometry results on the one hand, and GER parameters or $P_{\text {oes, }}$ lsp on the other hand (table 2).

Table 1. - Patient characteristics in the presence or absence of gastro-oesophageal reflux (GER)

\begin{tabular}{llll}
\hline & $\begin{array}{l}\text { GER+ } \\
(\mathrm{n}=27)\end{array}$ & $\begin{array}{c}\text { GER- } \\
(\mathrm{n}=46)\end{array}$ & p-value \\
\hline FEV1 \% pred & $79 \pm 3$ & $85 \pm 3$ & 0.19 \\
MEF25\% \% pred & $43 \pm 4$ & $52 \pm 4$ & 0.16 \\
MEF50\% \% pred & $50 \pm 4$ & $61 \pm 4$ & 0.07 \\
MEF75\% \% pred & $60 \pm 5$ & $72 \pm 4$ & 0.07 \\
$\beta$-agonist $\mu \mathrm{g} \cdot$ day $^{-1}$ & $353 \pm 87(\mathrm{n}=15)$ & $246 \pm 74(\mathrm{n}=31)$ & 0.38 \\
ICS $\mu \mathrm{g} \cdot \mathrm{day}^{-1}$ & $452 \pm 126(\mathrm{n}=14)$ & $512 \pm 104(\mathrm{n}=11)$ & 0.73 \\
PD20 $\mu \mathrm{g}$ & $230 \pm 89(\mathrm{n}=6)$ & $620 \pm 187(\mathrm{n}=14)$ & 0.23 \\
\hline
\end{tabular}

Values are mean \pm SEM. \% pred: percentage of predicted values; PD20: provocative dose of methacholine causing a $20 \%$ fall in FEV1; FEV1: forced expiratory volume in one second; MEF: mean expiratory flow of $25 \%, 50 \%$ and $75 \%$ of vital capacity; ICS: inhaled corticosteroids.

Table 2. - Correlation coefficients between spirometry parameters, asthmatic treatment and GER, NRE and Poes,Isp in the whole population

\begin{tabular}{lccr}
\hline & $\begin{array}{c}\text { \% of } 24 \mathrm{~h} \\
\text { with } \mathrm{pH}<4\end{array}$ & NRE & Poes,lsp \\
\hline FEV1 \% pred & 0.076 & -0.44 & 0.006 \\
MEF25\% \% pred & 0.098 & 0.122 & 0.052 \\
MEF50\% \% pred & 0.093 & 0.085 & 0.035 \\
MEF75\% \% pred & 0.005 & -0.28 & 0.047 \\
$\beta$-agonist (n=43) & -0.039 & -0.23 & -0.079 \\
ICS (n=67) & -0.152 & -0.87 & 0.062 \\
\hline
\end{tabular}

Poes,lsp: low oesophageal sphincter pressure; NRE: number of reflux episodes. For further definitions, see table 1. 
There was no difference in the percentage of $24 \mathrm{~h}$ with $\mathrm{pH}<4$ between patients classified according to asthma severity $(5.8 \pm 2.3 \%$ in grade 1 patients and $5.3 \pm 1.5 \%$ in grade 2 and 3 patients; $\mathrm{p}=0.93$ ). NRE was not different between these groups $(25 \pm 2$ in grade 1 patients; $\mathrm{n}=42$; versus $30 \pm 3.6$ in grade 2 and 3 patients; $\mathrm{n}=27$; $\mathrm{p}=0.21)$. $P_{\text {oes }}, 1 \mathrm{sp}$ was also similar in all groups $(2.0 \pm 0.1$ $\mathrm{kPa}(15.3 \pm 0.7 \mathrm{mmHg})$ in grade $1,(2.2 \pm 0.2 \mathrm{kPa}(16.6 \pm 1.3$ $\mathrm{mmHg}$ ) in grade 2 and 3 patients; $\mathrm{p}=0.17$ ).

There was no correlation between the quantitative requirement of antiasthma medications, both in terms of dosage and type of drug, and oesophageal acid exposure or $P$ oes,lsp (table 2). Theophylline users were equally distributed between GER-positive $(n=5)$ and GER-negative patients $(n=5)(p>0.05)$.

Stepwise regression analysis did not point out any factor significantly determining lung function in the whole population ( $p>0.05$ ) (table 3 ). Lung function parameters did not differ between patients with and without clinical signs of GER (table 4).

Finally, lung function parameters were compared between patients classified according to the NRE with a cut-off value of 15 episodes day $^{-1}$. The mean percentage of $24 \mathrm{~h}$ with $\mathrm{pH}<4$ was significantly different between the two groups $(7.6 \pm 1.9$ versus $1.1 \pm 0.26 ; p=0.04)$. No differences were found in GER and lung function parameters between the two groups (table 5). However, when taking into account patients with more than 15 reflux episodes $\cdot$ day $^{-1}$, a significant correlation was found between the NRE and bronchial reactivity, evaluated with methacholine PD20 ( $\mathrm{r}=0.561 ; \mathrm{p}=0.05 ; \mathrm{n}=12)$.

\section{Relationship between GER and lung function in the population of GER-positive asthma patients}

In GER-positive patients, we found no correlation between FEV1, MEF75\%, MEF50\%, MEF25\% and percentage of $24 \mathrm{~h}$ with $\mathrm{pH}<4, \mathrm{NRE}$ and $P$ oes,lsp. There

Table 3. - Step 1 correlation coefficients for potential digestive determinants of lung function

\begin{tabular}{lcccc}
\hline & FEV1 & MEF25\% & MEF50\% & MEF75\% \\
& $\%$ pred & $\%$ pred & $\%$ pred & $\%$ pred \\
\hline \% of 24 h with $\mathrm{pH}<4$ & 0.1 & 0.1 & 0.1 & 0.02 \\
Poes,lsp & 0.03 & 0.08 & 0.06 & 0.06 \\
\hline
\end{tabular}

For definitions, see tables 1 and 2.

Table 4. - Comparative analysis of spirometric values and GER parameters between patients with and those without clinical signs of GER

\begin{tabular}{lccc}
\hline & $\begin{array}{c}\text { Presence of } \\
\text { clinical signs of } \\
\text { GER (n=43) }\end{array}$ & $\begin{array}{c}\text { Absence of } \\
\text { clinical signs of } \\
\text { GER }(\mathrm{n}=40)\end{array}$ & p-value \\
\hline FEV1 \% pred & $82 \pm 3.4$ & $82 \pm 2.7$ & 0.98 \\
MEF25\% \% pred & $49 \pm 4.5$ & $48 \pm 3.9$ & 0.83 \\
MEF50\% \% pred & $58 \pm 4.5$ & $56 \pm 3.8$ & 0.85 \\
MEF75\% \% pred & $71 \pm 4.7$ & $66 \pm 4$ & 0.40 \\
PD20 & $242 \pm 137$ & $726 \pm 215$ & 0.07 \\
$\beta$-agonist & $339 \pm 64$ & $238 \pm 96$ & 0.37 \\
NRE & $28 \pm 3$ & $28 \pm 2$ & 0.94 \\
Poes,lsp & $14 \pm 0.8$ & $16 \pm 0.9$ & 0.04 \\
\% of 24 h & $7.1 \pm 2.5$ & $4.0 \pm 0.7$ & 0.26 \\
\hline
\end{tabular}

Values are mean \pm SEM. $\%$ of $24 \mathrm{~h}$ : percentage of $24 \mathrm{~h}$ with $\mathrm{pH}<4$. For further definitions, see tables 1 and 2 .
Table 5. - Comparative analysis of spirometric values between patients with more and those with less than 15 reflux episodes per $24 \mathrm{~h}$

\begin{tabular}{lccc}
\hline & $\begin{array}{c}>15 \\
\text { episodes } \cdot \text { day }^{-1}\end{array}$ & $\begin{array}{c}<15 \\
\text { episodes } \cdot \text { day }^{-1}\end{array}$ & p-value \\
\hline FEV1 \% pred & $82.2 \pm 2.7$ & $84.4 \pm 4.2$ & 0.66 \\
MEF25\% \% pred & $51.9 \pm 3.9$ & $43.6 \pm 4.6$ & 0.23 \\
MEF50\% \% pred & $60.3 \pm 3.9$ & $51.9 \pm 4.2$ & 0.22 \\
MEF75\% \% pred & $70.2 \pm 4.1$ & $64.5 \pm 5.8$ & 0.44 \\
$\beta$-agonists $\mu$ g.day ${ }^{-1}$ & $296 \pm 61$ & $266 \pm 179$ & 0.84 \\
ICS $\mu \mathrm{g} \cdot$ day $^{-1}$ & $480 \pm 100$ & $568 \pm 159$ & 0.63 \\
\hline
\end{tabular}

Values are mean \pm SEM. For definitions, see tables 1 and 2 .

Table 6. - Correlation coefficients between spirometry parameters, GER and Poes,Isp in the GER-positive asthma population

\begin{tabular}{llcc}
\hline & & & $\begin{array}{c}\text { \% of } 24 \mathrm{~h} \\
\text { with } \mathrm{pH}<4\end{array}$ \\
\hline FEV1 & NRE & Poes,lsp & -0.18 \\
MEF75\% & -0.234 & 0.7 & 0.246 \\
MEF50\% & -0.016 & 0.179 & 0.161 \\
MEF25\% & 0.133 & 0.401 & 0.345 \\
PD20 & $0.983 * * *$ & -0.317 & 0.341 \\
ICS & -0.109 & 0.274 & -0.276 \\
Inhaled $\beta$-agonist & -0.33 & 0.1 & -0.27 \\
\hline
\end{tabular}

***: $\mathrm{p}<0.001$. For definitions see tables 1 and 2 .

was no correlation between $\beta_{2}$-agonist use on one hand, and $P_{\text {oes, }}, 1 \mathrm{sp}(\mathrm{n}=14 ; \mathrm{r}=0.1 ; \mathrm{p}=0.7)$, the NRE $(\mathrm{n}=15 ; \mathrm{r}=-0.33$; $\mathrm{p}=0.23)$, and the percentage of $24 \mathrm{~h}$ with $\mathrm{pH}<4 \quad(\mathrm{n}=15$; $\mathrm{r}=-0.27 ; \mathrm{p}=0.34$ ) on the other.

However, there was a very strong correlation between PD20 and the NRE ( $n=6 ; r=0.983 ; p=0.001)$ (table 6).

There were no differences in GER parameters according to asthma severity in this group of GER-positive patients: percentage of $24 \mathrm{~h}$ with $\mathrm{pH}<4$ was $17.3 \pm 7.9$ in grade 1 and $8.9 \pm 2.4$ in grades 2 and $3(p=0.26)$; the number of reflux episodes were $33.5 \pm 5.5$ in grade 1 and $40.8 \pm 3.5$ in grade 2 and $3(\mathrm{p}=0.25) ; P_{\text {oes}}, 1 \mathrm{sp}$ was $2.0 \pm 0.2$ $\mathrm{kPa}(14.8 \pm 1.7 \mathrm{mmHg})$ in grade 1 and $2.2 \pm 0.3 \mathrm{kPa}$ $(16.8 \pm 2.0 \mathrm{mmHg})$ in grade 2 and 3 patients $(\mathrm{p}=0.46)$.

Stepwise regression analysis did not point out any relationship between lung function parameters and GER criteria in this group of patients.

\section{Discussion}

This study revealed a $32 \%$ prevalence of GER in a nonselected population of asthmatics attending our hospital out-patent clinic. In a subsample of the whole group, made up of patients with more than 15 reflux episodes $\cdot$ day $^{-1}$, a significant correlation between NRE and PD20 of methacholine was found. Moreover, a strong correlation was also shown in the group of GER-positive patients between NRE and PD20 of methacholine.

Other results were negative. No difference was observed in the lung function parameters of patients with and without clinical signs of GER, nor between GER-positive and GER-negative patients when GER was assessed on oesophageal $\mathrm{pH}$ monitoring data. Similar results were observed for antiasthmatic drugs, especially in the case of $\beta_{2}$-agonists. As recently observed and described by BousQueT et al. [20], mean dosage of ICS was lower than expected. There was no correlation between the 
severity of asthma, evaluated on spirometry parameters, and severity of GER. No relationship was observed between drug consumption, especially $\beta_{2}$-agonists, and GER or Poes,lsp. GER criteria (percentage of $24 \mathrm{~h}$ with oesophageal $\mathrm{pH}<4$; NRE) were not different in patients with different asthma severity, i.e. asthma grade.

The design and methodology of this study were planned to avoid as much bias as possible. Asthma was well characterized and well documented. All asthmatics, except those with digestive complaints, who presented consecutively to our out-patient allergy clinic were recruited. This pattern of inclusion rules out bias in patient selection. All spirometry tests were performed by the same physician. Digestive investigations, particularly oesophageal $24 \mathrm{~h} \mathrm{pH}$ monitoring, which is considered as the gold-standard assessment of GER, were performed in the same unit by the same two gastroenterologists. This allows the present study to define precisely the prevalence of GER in asthmatics, in comparison with other studies.

The absence of any relationship between lung function, drugs and GER parameters, except between NRE and bronchial hyperreactivity, minimizes the risk of missing any other relationship between asthma and GER in this study, even if interpretation of the results could be limited by the unknown real prevalence of GER in the general population.

The present study defined the prevalence of GER in asthmatics, in comparison with other studies. One hundred and ten healthy subjects were recently studied to define normal oesophageal $\mathrm{pH}$ values [17]. Results indicate that mean percentage of $24 \mathrm{~h}$ with oesophageal $\mathrm{pH}<4$ is 1.1 , varying from $0-8.6$, but no frequency above normal limit is given. GER was influenced by gender and age in this study, in contrast with our results. SonTAG and co-workers $[11,21]$ compared GER parameters in 104 consecutive asthmatics and in 40 healthy controls and observed a decreased lower oesophageal pressure and greater oesophageal acid exposure time in asthmatics as compared to controls. They did not compare the respective prevalence in each population, and did not clearly define how they characterized GER.

The only prevalence of GER known in the general population is defined by questionnaires searching for clinical signs of GER. This is not useful in the interpretation of the results of this study, since we observed that $50 \%$ of patients with GER had no clinical sign of it [22].

The present data support the relationship between bronchial hyperresponsiveness and GER, as a very strong correlation between PD20 of methacholine and NRE found. A relationship between GER and bronchial hyperresponsiveness was suggested by RAUSCHER et al. [23], who performed methacholine provocation before and after acid perfusion testing, and demonstrated a positive dose-dependent response between acid perfusion and bronchial hyperresponsiveness. These results were also supported by EкSTRÖм and TiBbLing [24], who measured bronchial hyperresponsiveness in parallel with FEV1 modification after acid perfusion testing, during which they demonstrated a positive correlation between PD20 of histamine and mean decrease in FEV1.

The percentage of $24 \mathrm{~h}$ with oesophageal $\mathrm{pH}<4$ is the most commonly used parameter for assessing GER.
This parameter is dependent both on the number of reflux episodes and their duration. It may have the same value with frequent reflux episodes of shorter duration and with scarcer episodes of longer duration. These data suggest that in asthmatics, the main determinant of the relationship between asthma and GER is the NRE.

Our results could be an explanation for the positive therapeutic results of HARDING et al. [25], who demonstrated the efficacy of acid suppressive therapy on asthma outcome.

In conclusion, gastro-oesophageal reflux was related neither to lung function nor to medical treatment in a nonselected population of asthmatics. The search for gastro-oesophageal reflux should then not be systematic in this population. A possible link between bronchial hyperresponsiveness and number of gastro-oesophageal reflux episodes is suggested.

Acknowledgements: The authors would like to thank J.F. Murray for help during the redaction of this manuscript and C. Pierard for help with translation.

\section{References}

1. Goldstein RA, Paul WE, Metcalfe DD, Busse WW, Reece ER. Asthma. Ann Intern Med 1994; 121: 698-708.

2. Boyle JT, Tuchman DN, Altschuler SM, Nixon TE, Pack AI, Cohen S. Mechanisms of the association of gastroesophageal reflux and bronchospasm. Am Rev Respir Dis 1985; 131: S16-S20.

3. $\quad$ Pope CE. Acid-reflux disorders. N Engl J Med 1994; 331: 656-660.

4. Spaulding HS, Mansfield LE, Stein MR, Sellner JC, Gremillion DE. Further investigation of the association between gastroesophagal reflux and bronchoconstriction. J Allergy Clin Immunol 1982; 69: 516-521.

5. Mansfield LE, Hameister HH, Spaulding HS, Smith NJ, Glab N. The role of vagus nerve in airway narrowing caused by intraesophageal hydrochloric acid provocation and esophageal distension. Ann Allergy 1981; 47: 431-434.

6. Schan CA, Harding SM, Haile JM, Bradley LA, Richter JE. Gastroesophageal reflux-induced bronchoconstriction: An intraesophageal acid infusion study using state-of-the-art technology. Chest 1994; 106: 731-737.

7. Wesseling G, Brummer RJ, Wouters EF, ten Welde GPM. Gastric asthma? No change in respiratory impedance during intraesophageal acidification in adult asthmatic. Chest 1993; 104: 1733-1736.

8. Larrain A, Carrasco J, Galleguillos J, Pope CE. Reflux treatment improves lung function in patients with intrinsic asthma. (Abstract). Gastroenterology 80: 1204.

9. Meier JH, McNally PR, Punja M, et al. Does omeprazole (prilosec) improve respiratory function in asthmatics with gastroesophageal reflux? A double blind, placebocontrolled crossover study. Dig Dis Sciences 1994; 39: 2127-2133.

10. Perrin-Fayolle M, Gormand F, Braillon G, et al. Long-term results of surgical treatment for gastroesophageal reflux in asthmatic patients. Chest 1989; 96: 40-45.

11. Sontag SJ, O'Connell S, Khaandelwal S, et al. Most asthmatics have GER with or without bronchodilator therapy. Gastroenterology 1990; 99: 613-620.

12. National Heart, Lung, and Blood Institute. International consensus report on diagnosis and treatment of asthma. Publication No. 92-3091; 1992. 
13. Nunn AJ, Gregg I. New regression equations for predicting peak expiratory flow in adults. $\mathrm{Br}$ Med J 1989; 298: 1068-1070.

14. Cropp CJA, Bernstein IL, Boushey HA, et al. Guidelines for bronchial inhalation challenges with pharmacologic and antigenic agents. Am Thorac Soc Bull 1980; 6: 11-19.

15. Charpin J, Orehek J, Vervloet D. Asthme bronchique. In: Charpin J, Vervloet D, eds. Allergologie. Flammarion. Paris, France, 1992.

16. Johnson LF, De Meester TR. Development of the 24-hour intraesophageal $\mathrm{pH}$ monitoring composite scoring system. J Clin Gastroenterol 1986; 8 (Suppl. 1): 52-58.

17. Richter JE, Bradley LA, DeMeester TR, Wu WC. Norma 24-hr ambulatory esophageal $\mathrm{pH}$ values. Influence of study center, pH electrode, age and gender. Dig Dis Science 1992; 37: 849-856.

18. Mosnier H, Leport J, Aubert A, Kianmanseh R, Idrissi SS, Guivarc'h M. A 270 degree laparoscopic posterior fundoplasty in the treatment of gastroesophageal reflux. J Am Col Surg 1995; 181: 220-224.

19. Ollyo JB, Fontolliet C, Brossard E, Lang F. Savary's new endoscopic classification of reflux oespohagitis. Acta Endoscopica 1992; 22: 307-314.

20. Bousquet J, Knani J, Henry C, Liard R, Richard A, Michel FB, Neukirch F. Undertreatment in a nonselected population of adult patients with asthma. $J$ Allergy Clin Immunol 1996; 98: 514-521.

21. Sontag SJ, Schnell TG, Miller TQ, et al. Prevalence of oesophagitis in asthmatics. Gut 1992; 33: 872-876.

22. Pechler S. Epidemiology and natural history of gastroesophageal reflux disease. Digestion 1992; 51 (Suppl. 1): $24-29$.

23. Rauscher H, Popp W, Ritschka L. Effect of short esophageal acidification on airway hyperreactivity. Respiration 1989; 55: 11-15.

24. Ekström T, Tibbling L. Esophageal acid perfusion, airway function, and symptoms in asthmatic patients with marked bronchial hyperresponsiveness. Chest 1989; 96 : 995-998.

25. Harding SM, Richter JE, Guzzo MR, Schan CA, Alexander RW, Bradley LA. Asthma and gastroesophageal reflux: acid suppressive therapy improves asthma outcome. Am J Med 1996; 100: 395-405. 